\title{
Using Artefactual Field Experiments to Learn about the Incentives for Sustainable Forest Use in Developing Economies
}

\author{
By Maarten Voors, Erwin Bulte, Andreas Kontoleon, \\ JOHN A. LIST, AND TY TURLEY困
}

\begin{abstract}
One vexing problem facing mankind is how to promote sustainable use of common property resources. Within developed and developing countries alike, misuse of fresh water, pastures, and forests is commonplace. While developed countries have in many cases designed principles and laws to promote sustainable resource use, developing countries often lack the institutional know-how and means to enforce property rights. This has led researchers to look for alternative means to address common property resource problems.

We study behavior and attitudes towards forest conservation in Sierra Leone and aim for two contributions related to common property resources. First, we attempt to establish if behavioral games, or, following the parlance of Glenn Harrison and John List (2004), artefactual field experiments (AFEs), can explain behavior in the field. If AFEs can explain variability in treatment of the commons, then we can have greater confidence in testing mechanisms in the laboratory and transferring the lessons learned to naturally occurring settings. This approach relies on the framework of Steven D. Levitt and John A. List (2007, hereafter LL), who propose that behavior in laboratory experiments is influenced by not
\end{abstract}

\footnotetext{
* Voors: Development Economics Group, Wageningen University, P.O. Box 8130, 6700 EW Wageningen, Netherlands (e-mail: maarten.voors@wur.nl); Bulte: Development Economics Group, Wageningen University, P.O. Box 8130, 6700 EW Wageningen, Netherlands (e-mail: erwin. bulte@wur.nl); Kontoleon: Department of Land Economy, University of Cambridge, 19 Silver Street, Cambridge CB3 9EP, United Kingdom (e-mail: ak219@cam.ac.uk); List: Department of Economics, The University of Chicago, 1126 East 59th Street, Chicago, IL 60637 (e-mail: jlist@uchicago. edu); Turley: Department of Economics, The University of Chicago, 1126 East 59th Street, Chicago, IL 60637 (e-mail: turley@uchicago.edu). We are indebted to the UK's Royal Society for the Protection of Birds (RSPB), the Gola Forest Programme, and Paul Richards and Esther Mokuwa for their collaboration in this project. We thank N.W.O. 452-04-333 and Cambridge Conservation Initiative (CCI 05/101005) for their financial support. We also thank our discussant Stephen V. Burks.
}

only monetary calculations but also by at least five other factors: (a) the presence of moral and ethical considerations, (b) the extent to which one's actions are scrutinized by others and the nature of that scrutiny, (c) the context in which the decision is embedded, (d) the subject pool of respondents, and (e) the stakes of the game.

The most straightforward version of the LL model predicts that behavior in AFEs will correlate perfectly with behavior in the field so that those who exhibit stronger social preferences in the lab will also do so in the field. The five factors in the LL model mentioned above serve as shift parameters, and if these shifters are isomorphic across people, then relative rankings are preserved across lab and field settings. The older psychology literature and more recent experimental work in economics provide evidence that suggests one should reject this most straightforward version of their model (see, e.g., Jetske Bouma, Erwin Bulte, and Daan van Soest 2008). Allowing heterogeneity in the shift parameters yields potentially very different relative rankings across the lab and field. Given that we both i) observe people in the lab (in AFEs) and ii) gather information on their behavior in the field (in a social intervention and in related surveys of household behavior), we can test whether relative rankings are preserved between the lab and field (see also Jon Anderson et al. 2010; Jeffrey Carpenter and Erika Seki forthcoming; and Devesh Rustagi, Stefanie Engel, and Michael Kosfeld 2010). If relative rankings are not preserved we can examine which observables explain heterogeneity in the shift parameters.

Our second contribution is to examine if social phenomena that are rarely explored, such as having a relative killed in civil war or living in a community with strong beliefs in witchcraft, directly influence social preferences and treatment of the common property resource. People in the Gola Forest region of southeastern Sierra Leone experienced high levels of violence during the civil war of 1992 to 2002. Witchcraft 
is also a significant problem in this area, with accusations and hiring of witch doctors a common occurrence.

\section{Experiments and Data}

We collected experimental and survey data in the region of the Gola Forest Reserve, in southeastern Sierra Leone. The Gola Forest is one of the largest remnants of the Upper Guinea forest in West Africa, a major stock of standing carbon, and a global biodiversity hotspot. However, it is located in one of the poorest regions in the world, torn by a recent civil war. Local populations depend to a large extent on forest-related goods and services. The Gola Forest Reserve was established in the 1920s and restricts the exploitation of resources within the designated area of the reserve. National laws dictate forest use and extraction behavior outside the reserve as well. While, strictly speaking, the reserve is located on private lands, it is essentially a regulated common pool resource providing locally and globally valued ecosystem services. In what follows we focus on extraction behavior and conservation efforts with respect to the forest reserve.

We ran two different field experiments related to public good games in the summer of 2010 in 35 villages across the seven chiefdoms constituting the Gola Forest region. These villages lie within one mile of the Gola forest. In total, 632 households participated in these studies. The first experiment was a social intervention meant to provide livelihood aid and mimic a public goods game ("PG Aid"). We endowed a representative from each household with $\$ 20$ (or $80,000 \mathrm{Le}$ ), more than a month's worth of unskilled wages. We then asked participants to divide this endowment between private goods for themselves and a community project fund for the entire village. On average, participants allocated 75 percent of their endowment to private livelihood support goods and 25 percent to a community project fund.

The second experiment was a conventional public goods game ("PGG") with three players. Players were endowed with 5 tokens. Every token kept was worth $\$ 0.25$ (or 1,000 Le) and each token invested was worth half that to all players in the group. The payoff under full cooperation amounted to 7,500 Le, and the maximum possible payoff for a free rider (assuming his peers invested their complete endowment in the public good) was 10,000 Le. On average households invested 2 tokens in each round with an average payoff of 6,000 Le.

Interestingly, and somewhat to our surprise, behaviour in the two games is uncorrelated ( $\rho=0.04, p=0.33)$. The framework of LL suggests several explanations for the differences in measured behavior. The stakes are much higher in $P G$ Aid than in $P G G$. Moreover, $P G$ Aid is framed as a livelihood support initiative, so the context within which the decision is embedded also varies. This suggests applying the outcomes of one particular PG experiment and interpreting them as "the proxy" for social preferences may be problematic. We therefore include both types of behavior as explanatory variables in the regression analysis that follows.

We also collected data with household and village level surveys, ascertaining demographic, socioeconomic, institutional, and conflict related information. We collected survey data in 25 of the 35 villages included in the study and sampled 170 households from the 632 participating in the AFEs. The household surveys provided data on behavioral and attitudinal variables related to forest management and use. The three dependent variables we focus on in this paper are: (i) "commercial interests," a variable indicating the degree to which an individual is involved in business with commercial mining, logging, or hunting activities that violate national law as well as local by-laws (mean: 4.5, standard deviation: $1.5)$; (ii) "illegal extraction," the total per capita value (consumption and sales) of illegally hunted animals, typically endangered species (mean: 5,485 Le, standard deviation: 20,430); and (iii) "pro conservation," the answer to a five-point scale question, Do you support conserving the Gola Forest? (mean: 3.2, standard deviation: 1.5).

We include a series of conventional household controls (age, income, education) and use community fixed effects to control for intercommunity heterogeneity. In addition, we include two unconventional household variables that we believe are relevant in the Sierra Leone context. First, we expect victims of civil war violence to display more prosocial behavior (John Bellows and Edward Miguel 2006), so we control for

\footnotetext{
${ }^{1}$ Additive scale from 0 to 8 based on answers to, Do you think that miners, traders, and loggers are welcome in your village? and, Do you do business with the commercial miners, and/or hunters, and/or loggers?
} 
household exposure to violence during the war in the 1990s. Second, we control for witchcraft beliefs, which we hypothesize are a mechanism to enforce social norms in Africa (JeanPhilippe Platteau 2000). While economists have studied witchcraft before (e.g., Edward Miguel 2005), such work has focused on the causes of witchcraft accusations, not the consequences. Witchcraft may have evolved to enforce social order and facilitate punishment in the event of failure to provide public goods.

The estimation strategy at this stage is exploratory and aims at unearthing robust correlations. It does not aim to fully address endogeneity issues; this is left for future work.

\section{Regression Results}

To analyze how social preferences and household characteristics are associated with forest conservation, we estimate the six models in Table 1 with village-level fixed effects and a range of relevant individual controls. These models include each of the three conservation outcomes identified above. To explore evidence of heterogeneity in shift parameters, as discussed by LL, we also introduce a full set of interaction terms.

When simply considering the signs of the coefficients for the two experimental variables $(P G G$ and $P G A i d)$, where higher values mean more public spiritedness, we observe they tend to match intuition. Specifically, more "prosocial play" in $P P G$ and $P G$ Aid tends to be correlated with (i) a reduced willingness to interact with commercial parties with commercial interests damaging the forest and its biodiversity; (ii) a lower level of involvement in the illegal extraction of wildlife; and (iii) more positive attitudes towards forest conservation. However, the latter finding is true only for $P G$ Aid; the reverse is true for $P G G$, which enters with the "wrong sign" in column 5.

This counterintuitive result, however, should perhaps not be unexpected in light of the earlier remark about the lack of correlation between behavioral play in the two PG experiments. $P G G$ and $P G$ Aid enter "differently" across many of our models. While both $P G G$ and $P G$ Aid enter significantly in the interaction model explaining "commercial interests," we find that only $P G$ Aid is correlated with illegal extraction. Moreover, $P G$ Aid and $P G G$ enter with opposite signs in the "proconservation" models and enter significantly only in different specifications.
Our three dependent variables are intended to capture related dimensions of the household's willingness to contribute to the provision of a public good (sustainable forest management). However, it appears that these dimensions are somehow "distinct" in the sense that they correlate with different behavioral proxies and controls. Taken together, we interpret this as evidence that social preferences for conservation may be unstable or highly context dependent.

Turning to the issue of heterogeneity, a few insights stand out. Importantly, including interaction terms matters. For the PG explanatory variables, coefficient size tends to increase, as does the significance level. When we include interaction terms, $P G G$ and $P G$ Aid enter significantly in the "commercial interest" model. Including them also alters the significance of the PG proxies in the "proconservation" model. We interpret this as strong evidence of heterogeneity in the mapping between lab and naturally occurring behavior.

Although some of the interaction terms are significant, they are not consistently so across our dependent variables. No interaction term is significant in the illegal extraction model. Interestingly, the unconventional control variables interacted with AFE play especially seem to have explanatory power. The witchcraft and war violence interaction terms are sometimes significant, while interaction terms based on the conventional controls (age, education, and income) tend to be not significant. These controls are substantively social, and we would expect them to influence the mapping of social preferences between lab and real world behavior. Education interacted with $P G G$ also enters with a positive correlation in the pro conservation model, and it could be argued that education is also a social phenomenon. Hence, heterogeneity matters, but one should think about social factors in particular when considering the dimensions along which to explore heterogeneity.

Finally, turning to our controls, we note that age and income are not significantly correlated with common pool management and attitudes towards conservation when controlling for behavior in the experiments. Education is negatively correlated with illegal extraction, but also with proconservation preferences, a mixed outcome. Respondents who state that witchcraft is a problem in the village tend to be the same ones consorting with private parties with 
Table 1-Experimental Play and Forest Conservation

\begin{tabular}{|c|c|c|c|c|c|c|}
\hline & $\begin{array}{l}\text { Commercial } \\
\text { interests } \\
(1)\end{array}$ & $\begin{array}{l}\text { Commercial } \\
\text { interests } \\
(2)\end{array}$ & $\begin{array}{c}\text { Illegal } \\
\text { extraction } \\
\text { (3) }\end{array}$ & $\begin{array}{c}\text { Illegal } \\
\text { extraction } \\
(4)\end{array}$ & $\begin{array}{c}\text { Pro } \\
\text { conservation } \\
(5)\end{array}$ & $\begin{array}{c}\text { Pro } \\
\text { conservation } \\
(6)\end{array}$ \\
\hline PG aid & $\begin{array}{c}-0.00000307 \\
(0.00000940)\end{array}$ & $\begin{array}{c}-0.0000900 * \\
(0.0000525)\end{array}$ & $\begin{array}{r}-0.395^{*} \\
(0.236)\end{array}$ & $\begin{array}{c}-2.259 * * \\
(1.111)\end{array}$ & $\begin{array}{c}0.00000415 \\
(0.00000754)\end{array}$ & $\begin{array}{c}0.0000748^{*} \\
(0.0000442)\end{array}$ \\
\hline PGG & $\begin{array}{c}-0.145 \\
(0.108)\end{array}$ & $\begin{array}{c}-0.275^{*} \\
(0.142)\end{array}$ & $\begin{array}{c}-2,281.2 \\
(2,157.8)\end{array}$ & $\begin{array}{c}-2,663.8 \\
(3,091.1)\end{array}$ & $\begin{array}{r}-0.213^{*} \\
(0.123)\end{array}$ & $\begin{array}{c}-0.179 \\
(0.158)\end{array}$ \\
\hline Age & $\begin{array}{c}-0.00869 \\
(0.00591)\end{array}$ & $\begin{array}{r}-0.00805 \\
(0.0201)\end{array}$ & $\begin{array}{l}-74.95 \\
(173.0)\end{array}$ & $\begin{array}{c}5.248 \\
(443.9)\end{array}$ & $\begin{array}{c}-0.00745 \\
(0.00621)\end{array}$ & $\begin{array}{c}0.0250 \\
(0.0197)\end{array}$ \\
\hline Education level & $\begin{array}{c}0.0346 \\
(0.0780)\end{array}$ & $\begin{array}{c}-0.669 \\
(0.420)\end{array}$ & $\begin{array}{c}-2,001.5^{*} \\
(1,136.8)\end{array}$ & $\begin{array}{c}-9,012.9 * \\
(5,273.3)\end{array}$ & $\begin{array}{l}-0.204 * * * \\
(0.0710)\end{array}$ & $\begin{array}{c}-0.580^{*} \\
(0.323)\end{array}$ \\
\hline Total household income & $\begin{array}{c}0.00418 \\
(0.0299)\end{array}$ & $\begin{array}{c}-0.0492 \\
(0.0920)\end{array}$ & $\begin{array}{c}-349.7 \\
(798.6)\end{array}$ & $\begin{array}{c}-1,602.4 \\
(2,689.2)\end{array}$ & $\begin{array}{l}-0.0720 * * \\
(0.0287)\end{array}$ & $\begin{array}{c}0.0536 \\
(0.106)\end{array}$ \\
\hline Witchcraft is a problem & $\begin{array}{c}0.161 * \\
(0.0985)\end{array}$ & $\begin{array}{l}0.178^{*} \\
(0.106)\end{array}$ & $\begin{array}{c}2,541.0 \\
(2,608.0)\end{array}$ & $\begin{array}{c}2,215.5 \\
(2,593.0)\end{array}$ & $\begin{array}{c}0.144 \\
(0.109)\end{array}$ & $\begin{array}{l}0.176 \\
(0.127)\end{array}$ \\
\hline Family member died due to War & $\begin{array}{c}0.880^{*} \\
(0.473)\end{array}$ & $\begin{array}{r}-3.804^{*} \\
(2.093)\end{array}$ & $\begin{array}{r}-5,692.4 \\
(8,122.6)\end{array}$ & $\begin{array}{c}822.4 \\
(35,269.1)\end{array}$ & $\begin{array}{c}0.545 \\
(0.399)\end{array}$ & $\begin{array}{l}-5.238 * * \\
(2.112)\end{array}$ \\
\hline Age $\times$ PG aid & & $\begin{array}{c}0.000000386 \\
(0.000000472)\end{array}$ & & $\begin{array}{r}-0.00110 \\
(0.00933)\end{array}$ & & $\begin{array}{c}-0.000000469 \\
(0.000000512)\end{array}$ \\
\hline Education $\times$ PG aid & & $\begin{array}{c}0.0000200 \\
(0.0000136)\end{array}$ & & $\begin{array}{c}0.269 \\
(0.171)\end{array}$ & & $\begin{array}{c}-0.00000133 \\
(0.00000844)\end{array}$ \\
\hline Income $\times$ PG aid & & $\begin{array}{c}0.00000235 \\
(0.00000372)\end{array}$ & & $\begin{array}{l}0.100 \\
(0.0659)\end{array}$ & & $\begin{array}{c}-0.00000241 \\
(0.00000236)\end{array}$ \\
\hline Witchcraft $\times$ PG aid & & $\begin{array}{c}0.0000171 \\
(0.0000185)\end{array}$ & & $\begin{array}{c}0.649 \\
(0.484)\end{array}$ & & $\begin{array}{c}-0.0000643 * * * \\
(0.0000194)\end{array}$ \\
\hline War dead $\times$ PG aid & & $\begin{array}{c}0.0000586 \\
(0.0000410)\end{array}$ & & $\begin{array}{c}1.197 \\
(0.944)\end{array}$ & & $\begin{array}{c}0.0000410 \\
(0.0000448)\end{array}$ \\
\hline Age $\times$ PGG & & $\begin{array}{c}-0.00443 \\
(0.00581)\end{array}$ & & $\begin{array}{l}-32.06 \\
(167.7)\end{array}$ & & $\begin{array}{c}-0.00925 \\
(0.00777)\end{array}$ \\
\hline Education $\times$ PGG & & $\begin{array}{l}0.125 \\
(0.0823)\end{array}$ & & $\begin{array}{c}1,027.0 \\
(1,254.5)\end{array}$ & & $\begin{array}{c}0.142 * \\
(0.0838)\end{array}$ \\
\hline Income $\times$ PGG & & $\begin{array}{c}0.0177 \\
(0.0263)\end{array}$ & & $\begin{array}{l}-91.02 \\
(648.7)\end{array}$ & & $\begin{array}{c}-0.0329 \\
(0.0328)\end{array}$ \\
\hline Witchcraft $\times$ PGG & & $\begin{array}{c}0.638 \\
(0.497)\end{array}$ & & $\begin{array}{c}6,080.6 \\
(5,550.4)\end{array}$ & & $\begin{array}{c}0.692 \\
(0.460)\end{array}$ \\
\hline War dead $\times$ PGG & & $\begin{array}{l}2.065 * * \\
(0.951)\end{array}$ & & $\begin{array}{c}-1,7791.5 \\
(14,182.1)\end{array}$ & & $\begin{array}{l}2.667 * * * \\
(0.941)\end{array}$ \\
\hline Constant & & & $\begin{array}{c}13,881.5 \\
(11,275.4)\end{array}$ & $\begin{array}{c}44,319.4 \\
(28,664.6)\end{array}$ & & \\
\hline Community FE & Yes & Yes & Yes & Yes & Yes & Yes \\
\hline Observations & 99 & 99 & 104 & 104 & 103 & 103 \\
\hline$R^{2}$ & 0.06 & 0.10 & 0.19 & 0.25 & 0.09 & 0.14 \\
\hline
\end{tabular}

Note: Robust standard errors in parentheses.

*** Significant at the 1 percent level.

**Significant at the 5 percent level.

* Significant at the 10 percent level.

commercial interests. Perhaps this reflects that such individuals stand to lose more from informal enforcement of bylaws associated with forest conservation. Exposure to war also appears to be relevant. For example, in the "commercial interests" model it enters directly, but also via the interaction term. Interestingly, and reflecting some of the discussion above, the interaction term with $P G G$ is significant, but the interaction term with $P G$ Aid is not. The direct effect of war on conservation is negative, but this is mediated via increased sharing in the $P G G$.

\section{Concluding Remarks}

We have explored the relation between behavior in two distinct field experiments and various forest conservation behaviors and attitudes. One 
main result is that there does not appear to be one simple metric of prosocial preferences. There is no correlation between behavior as measured in the two experiments, and no robust pattern of correlations between play in the games and conservation behavior and attitudes in the real world.

This result is consistent with an oft-found result in psychology on the weak correlations between behaviors in different settings (even across lab settings; see, e.g., Walter Mischel 1968; Lee Ross and Richard E. Nisbett 1991, for reviews). For instance, Hugh Hartshorne and Mark A. May (1928) find evidence that the same people are not consistently the cheaters in different situations. For general experimental purposes, that does not mean that there is something necessarily wrong with one of the experimental situations in this study. Rather, it means that either "(a) there is not a general cross-situational trait called "[treating the commons with care]," and/or (b) the subjects view one situation as relevant to [managing the commons] and one as irrelevant" (Levitt and List 2007, 160-1).

Our second main result is that heterogeneity matters. It may not be feasible to assume a parallelism between laboratory evidence and the real world. Individuals behaving in a prosocial manner in the lab may not necessarily be the same individuals who provide most of the public goods in the field. Other mitigating factors should be identified and incorporated into models of social preferences. NGOs and government agencies should not expect to be able to testbed interventions and select the most responsive partners for project interventions based on simple behavioral games.

\section{REFERENCES}

Anderson, Jon, Matthew Bombyk, Stephen Burks, Jeffrey Carpenter, Derek Ganzhorn, Lorenz Goette, and Aldo Rustichini. 2010. "Lab Measures of Other-Regarding Behavior Predict some Choices in a Natural On-The-Job
Social Dilemma: Evidence from the Truckers and Turnover Project." Unpublished.

-Bellows, John, and Edward Miguel. 2006. "War and Institutions: New Evidence from Sierra Leone." American Economic Review, 96(2): 394-99.

-Bouma, Jetske, Erwin Bulte, and Daan van Soest. 2008. "Trust and Cooperation: Social Capital and Community Resource Management." Journal of Environmental Economics and Management, 56(2): 155-66.

Carpenter, Jeffrey, and Erika Seki. Forthcoming. "Do Social Preferences Increase Productivity? Field Experimental Evidence from Fishermen in Toyama Bay." Economic Inquiry.

Hartshorne, Hugh, and Mark A. May. 1928. Studies in Deceit. Vol. 1, Studies in the Nature of Character. New York: MacMillan.

-Harrison, Glenn, and John A. List. 2004. "Field Experiments." Journal of Economic Literature, 42(4): 1009-55.

-Levitt, Steven D., and John A. List. 2007. "What Do Laboratory Experiments Measuring Social Preferences Reveal about the Real World?" Journal of Economic Perspectives, 21(2): 15374.

Miguel, Edward. 2005. "Poverty and Witch Killing." Review of Economic Studies, 72(4): 1153-72.

Mischel, Walter. 1968. Personality and Assessment. Mahwah, NJ: Lawrence Erlbaum Associates.

Platteau, Jean-Philippe. 2000. Institutions, Social Norms, and Economic Development. Vol.1, Fundamentals of Development Economics. Reading, UK: Harwood Academic.

Ross, Lee, and Richard E. Nisbett. 1991. The Person and the Situation: Perspectives of Social Psychology. New York: McGraw-Hill.

- Rustagi, Devesh, Stefanie Engel, and Michael Kosfeld. 2010. "Conditional Cooperation and Costly Monitoring Explain Success in Forest Commons Management." Science, 330(6006): 961-65. 